\title{
The Effect of Bundle Adaptation Control on VAP Speed and Length of Hospital Stay in Avoiding the Ventilator Associated Pneumonia (VAP) at Anesthesia Intensive Care Unit
}

\author{
Şerife Karagözoğlu ${ }^{1^{*}}$, Fatma Tok Yildiz ${ }^{1}$, Sinan Gürsoy ${ }^{2}$, Expert Nurse Zuhal Gülsoy², Burcu Kübra Süha ${ }^{1}$, Hülya Koçyiğit ${ }^{1}$, \\ Nazif Elaldi ${ }^{2}$ and Gonca Arslan ${ }^{2}$ \\ ${ }^{1}$ Faculty of Health Science, Cumhuriyet University, Sivas, Turkey \\ ${ }^{2}$ Faculty of Medicine, Cumhuriyet University, Sivas, Turkey
}

\begin{abstract}
Introduction: This study was conducted in order to evaluate the adaptation control onVAP prevention bundle adaptationcontrol in terms of VAP speed, length of stay at hospital and adaptation of healthcare staff to bundle application.

Method: The data of the study, which was conducted in cross sectional pattern on controlled and uncontrolled groups for ten months each, was gathered via Introductory Features Form, VAP Prevention Bundle Application List and VAP Prevention Bundle Control List. Gathered data was presented in numbers, percentages, averages and standard deviations. The data was analyzed via chi square test, Mann-Whitney $U$ and Kruskal-Wallis tests.

Results: It was found out that the length of stay at hospital for controlled group (X=11.41 \pm 12.29$)$ is fairly shorter than of uncontrolled group $(\mathrm{X}=31.41 \pm 36.41)$; and it was also found out that, in comparison with the controlled group (4.7\%) the VAP development rate is higher with the uncontrolled group (19.6\%) and the difference in percentages is statistically meaningful. With the uncontrolled group the VAP speed is measured as 7.12 ventilator days while the time is 4.14 with the controlled group; and difference in time spent on mechanical ventilator is found to be statistically highly meaningful. In this study, it was found out that the adaptation rate of doctors and nurses working at ICUs to ventilator bundle are $69.89 \%$.

Conclusion: In accordance with the gathered data, it was determined that, controlled and uncontrolled groups have similar characteristics in terms of introductory features; although the adaptation rate with controlled group is lower than the average numbers in literature, while the VAP rate and speed is higher with the uncontrolled group, these numbers decrease to statistically meaningful levels with the controlled group. In our study it was observed that, in comparison with the uncontrolled group, the length of time spent at hospital and on mechanical ventilator is statistically shorter with the controlled group.
\end{abstract}

\section{Introduction}

Ventilator-associated pneumonia (VAP), which is defined as pneumonia that occurs within 48 hours after intubation with patients, who did not have pneumonia prior to intubation, receiving mechanical ventilation during the intubation, increases risk of mortality, days spent on mechanical ventilator, length of time spent at hospital and cost of care in critically ill patients [1-3]. VAP is a complicated condition in terms of diagnosis and treatment, and it is also a priority condition that should be prevented in clinical settings $[4,5]$. For this reason, prevention of VAP in ICUs is considered as an important practice for patient safety and an indication of health care quality. The incidence rate of VAP varies according to the type of ICUs, hospital and country. The Centers for Disease Prevention and Control-CDC 2018 has determined the VAP rates as 6 to 13.3/103 ventilator days in adult intensive care units, 7.3 to 103 ventilator days in internal ICUs, and 13.2 to 103 ventilator days in surgical intensive care units. In our country, in National Hospital Infection Surveillance Web of Department of Health's 2014 report, the VAP number is calculated as 3467 and $7.6 \%$ in 456956 mechanical ventilator days in anesthesiology - reanimation ICUs [6].

In spite of the guidelines developed recent years, VAP development in ICUs is still a serious issue [7] and extra financial and clinical charge originated by VAP development is an indisputable fact [5]. Nevertheless, it is to our knowledge that only the half of the patients staying at intensive care units are administered with clinically proven, up-to-date VAP preventive treatment [8]. On the other hand, Institute for Healthcare Improvement (IHI) reports that applying only one proven method is not enough to prevent hospital infections, in accordance with recently carried out studies. Therefore, in order to achieve the goals of care and to increase adaptationin standardized applications, the term "care bundle" was put forward in terms of idealized regulations in ICUs. In this manner, idealized ICUs are parts of healthcare institutions which bring VAP risk preventive measurements to forefront [1]. Because, decreasing VAP incidence ratio in intensive care units is regarded as a significant indicator of quality in terms patient safety [5]. In order to get this objective, following strategies such as team work under IHI Ventilator Bundle Guidelines, coordinated multi-discipliner patient visits, determination of daily goals, administration of scientifically proven treatment techniques and removing the mechanical ventilators as soon as possible, many health institutes aim to achieve significant decrease in VAP incidence speed [9].

"Corresponding Author: Prof. Şerife Karagözoğlu, Faculty of Health Science Cumhuriyet University, Sivas, Turkey; E-mail: serifekaragozoglu@gmail.com

Citation: Karagözoğlu Ş, Yildiz FT, Gürsoy S, Gülsoy Z, Süha BK, et al (2018) The Effect of Bundle Adaptation Control on VAP Speed and Length of Hospital Stay in Avoiding the Ventilator Associated Pneumonia (VAP) at Anesthesia Intensive Care Unit. Int J Nurs Clin Pract 5: 295, doi: https://doi. org/10.15344/2394-4978/2018/295

Copyright: () 2018 Karagözoğlu et al. This is an open-access article distributed under the terms of the Creative Commons Attribution License, which permits unrestricted use, distribution, and reproduction in any medium, provided the original author and source are credited. 
Citation: Karagözoğlu Ş, Yildiz FT, Gürsoy S, Gülsoy Z, Süha BK, et al. (2018) The Effect of Bundle Adaptation Control on VAP Speed and Length of Hospital Stay in Avoiding the Ventilator Associated Pneumonia (VAP) at Anesthesia Intensive Care Unit. Int J Nurs Clin Pract 5: 295. doi: https://doi.org/10.15344/2394$4978 / 2018 / 295$

Page 2 of 7

In accordance with scientifically proven clinical application guidelines, ventilator bundles contribute to the best healthcare service available [1]. Ventilator bundles are groups of approaches which can contribute to recovery process of patients when they are administered on their own, but these approaches bring a lot more success when administered as a whole $[1,10]$. According to IHI guideline, ventilator bundle must be designed by a multi-discipliner team, and the bundle must be as small and efficient as possible. Ventilator bundle must consist of 3 to 5 scientifically proven applied and preventive paces, each should be able to applied on its own and each must be able to contribute to quality of scientifically proven care method $[1,10,11]$. In the 100.000 Lives (2006) campaign of IHI, it was reported that VAP did not develop on patients of controlled groups who were staying at 14 different hospitals and administered with ventilator bundles [1]. In their VAP Prevention Guideline (2006), IHI recommended the four approaches of mechanical ventilator bundle as: elevation of bedhead around $30-45^{\circ}$, daily sedation check and fast extubation, peptic ulcer prophylaxis and deep vein thrombosis; in 2010, included daily oral care with chlorhexidine to the list; and in 2012 updated the ventilator bundle to its current form $[1,10]$.

In the literature, there are numerous international [4,12-17] and national [18-20] studies which were carried out in order to find out the efficiency of application of ventilator bundle on VAP development speed. In these studies, it was proven that it is possible to decrease the VAP development speed significantly and it is even possible to fully prevent VAP development via application of ventilator bundle. In our country, there are two proficiency and a $\mathrm{PhD}$ thesis which focus on the issue [18-20]. Yildız [18] evaluated adaptation of anesthesiology and neurology ICUs staff to 5 approaches ventilator bundle which was updated by IHI in 2012. In Ylldiz's study, it was found out that full adaptation to updated ventilator bundle was 30.5\%, VAP did not develop with patients of full adaptation and there is statistically significant correlation between ventilator bundle adaptationand VAP development [18]. In another study, which was carried out by Sungur [19] in order to find out the success of eight approaches ventilator bundle that applies elevation of bedhead around $30-45^{\circ}$, endotracheal pressure of $20-25 \mathrm{cmH}_{2} \mathrm{O}$, subglottic aspiration, closed system aspiration, chlorhexidine oral care, sedation pause, deep vein thrombosis prophylaxis and peptic ulcer prophylaxis, it was found out that no significant decrease in VAP surveillance was observed prior to and during the application of ventilator bundle. In a study carried out by Kilınçalp [20], it was found out that, with $92.3 \%$ adaptation to nine approach ventilator bundle (peptic ulcer and deep vein thrombosis prophylaxis, elevation of bedhead, subglottic aspiration, oral care, removal of ventilator, aseptic application of aspiration, monitoring of cuff pressure, cleaning the ventilator parts/prevention of liquid accumulation) VAP speed dropped from $14.7 / 103$ days to $3.28 / 103$ days.

Aim of the ventilation bundles is practicing clinically proven application guidelines, standardization of care techniques and enhancing healthcare approaches. In the literature there are numerous studies that are conducted in order to find out effects of ventilator bundle applications on VAP speed, and the approaches and their numbers differ in accordance with the studies which are mainly carried out by single disciplines [19-26]. Contrary to these mono-discipliner studies, our study was conducted on controlled and uncontrolled groups for 10 months for each by a multi-discipliner team of anesthesiologists, specialists, medical students, nurses, infectious diseases specialists and nurses, academicians and clinic nurses. With our study, we believe that we have contributed to decreasing VAP incidence ratio significantly in the intensive care unit where we conducted our study, shortening the time spent on mechanical ventilator and at hospital, including VAP prevention bundle into the standardized procedures of the institution, and increasing the awareness level of the team, which have conducted the study, on significance of ventilator bundle application.

\section{Objective}

This study was conducted in order to evaluate the adaptation of VAP prevention bundle adaptation control in terms of VAP speed, length of stay at hospital and adaptation of healthcare staff to bundle application.

\section{Material and Method}

\section{Type of the study}

The study is of cross-sectional pattern.

\section{Population and sample}

Sample of this study, which was conducted in cross-sectional pattern on controlled and uncontrolled groups for ten months each, includes 94 patients (Uncontrolled group: 51; Controlled group: 43) whose medical needs correspond to aims of the study and willingly took part or allowed to take part in it, and stayed at Intensive Care Unit of Anesthesiology and Reanimation Department of a university hospital from 01.05.2016 to 01.01.2018.

\section{Inclusion criteria}

Patients, who (1) are staying at intensive care unit, (2) are 18 or over, (3) stayed at intensive care unit for 48 hours or longer and intubated with mechanical ventilator, (4) were intubated in another service, observed less than 24 hours and transferred to intensive care unit, were included into the study.

\section{Exclusion criteria}

Patients, who (1) were diagnosed with pneumonia while hospitalization or transfer to intensive care unit, or were diagnosed with pneumonia longer than 48 hours ago, (2) had oral surgery, (3) are bleeding, can not take antithrombotic treatment and can not be moved, (4) have depressed immune system, currently taking chemotherapeutic agents as immune-suppressive medication or took them within past 30 days, were excluded from the study.

\section{Data Collection Tools}

In order to gather data, (1) Introductory Features Form, (2) VAP Prevention Bundle Application List which was designed in accordance with the current literature $[4,12-20,24]$ and (3) VAP Prevention Bundle Control List were utilized.

Introductory Features Form: This form consists of 11 questions including patient's and companion's first names and family names, age, gender, diagnosis, date of hospitalization, administration date of mechanical ventilation, respiratory condition, date of discharge, number of days spent at hospital, length of time on mechanical ventilation, former clinic and reason of hospitalization. 
Citation: Karagözoğlu Ş, Yildiz FT, Gürsoy S, Gülsoy Z, Süha BK, et al. (2018) The Effect of Bundle Adaptation Control on VAP Speed and Length of Hospital Stay in Avoiding the Ventilator Associated Pneumonia (VAP) at Anesthesia Intensive Care Unit. Int J Nurs Clin Pract 5: 295. doi: https://doi.org/10.15344/2394$4978 / 2018 / 295$

Page 3 of 7

VAP Prevention Bundle Application List (VAP-PBAL): This list, which is applied to controlled group patients, consists of a chart of 31 days and four questions as follows: first name and family name of the patient, bed number, VAP situation and if developed on which day of the ventilation did the VAP occur. The chart is a medium of documentation which is filled by clinical specialists and nurses for each shift in accordance and adaptation with approaches included into the ventilator bundle.

VAP Prevention Bundle Control List (VAP-PBCL): This list was designed in order to check the adaptation of doctors and nurses to ventilator bundle. The list consists of three parts containing first and family name of the patient, bed number and control date, and a chart application condition of ventilation bundle in accordance with 08$16,16-24$ and $24-08$ shifts. The chart is a medium of documentation which is filled by chief doctor and nurse of the department together at 08:30 - 09:00 in the morning after 24 hours of ventilator application.

\section{Application of the study}

This study was carried out on controlled and uncontrolled phases for 10 months each. On the first phase, routine applications were carried out in the clinic for ten months. As the routine application, 11 approaches VAP prevention bundle was utilized, which was recommended by infections control committee of the institution. The approaches included in the routine bundle are (1) disinfection of hands before contact with the patient, (2) elevation of bedhead around $30-45^{\circ}$, (3) monitoring of cuff pressure, (4) cleaning the ventilator/ prevention of liquid accumulation, (5) evaluation of aspiration requirements and aspiring the patient with aseptic technique, (6) removing the ventilator, (7) oral care for three times at least, (8) avoiding unplanned ex-tubation and re-intubations, (9) peptic ulcer prophylaxis, (10) deep vein thrombosis prophylaxis, (11) and daily sedation pause. At this phase of the study, doctors and nurses were not inspected but utilizing the identifier form only records were gathered which contains data about VAP development situation, and if developed on which day of the ventilation it occurred.

The second part of the study includes the ten months controlled phase. At this phase, the routine ventilation bundle was reevaluated by study team and redesigned in compliance with IHI's updated VAP Prevention Guidelines of 2012. The redesigned ventilator bundle consists of 5 approaches; (1) elevation of bedhead around 30-450, (2) evaluation of daily sedation, (3) peptic ulcer prophylaxis, (4) deep vein thrombosis prophylaxis and (5) daily oral care with chlorhexidine. While all VAP preventive approaches were continued to be applied on routine in uncontrolled phase, the 5 approaches corresponding to study approaches were carried out under control. For this reason, before the initiation of the study, doctors and nurses working at ICU were informed at a briefing about the approaches that are included in the re-designed ventilator bundle. This briefing was done again when a new staff is included into the ICU team or when was needed.

VAP-PBAL forms were filled in by doctors and nurses who are giving the routine care and treatment to the patients in intensive care unit at each shift $(08.00-16: 00,16.00-24.00,24.00-08.00)$. VAPPBCL forms were filled in by chief the doctor and nurse in charge of evaluation of the study at 08.30-09.00 upon visiting the patients included into the study after checking the VAP-PBAL forms.

VAP development conditions data and the day of VAP beginning of patients who were observed during controlled and uncontrolled phases, was gathered from Hospital Infection Control Committee records. The pneumonia that occurred with patients who were mechanically ventilated with intubation for longer than 48 hours in intensive care unit, diagnosed by infectious diseases specialist of research team according to clinical, laboratory and radiological symptoms.

\section{Ethics of the Study}

Before the initiation of the study, Sivas Cumhuriyet University, Faculty of Medicine's Clinical Studies Ethics Committee's approval (Resolution Number: 2016-12/17) was taken and written permission of Sivas Cumhuriyet University, Healthcare Research Hospital's Anesthesiology and Reanimation Department's Intensive Care Unit, was taken. Upon informing the participant patients and their relatives, and taking written permission form from them, the data was gathered by research team. The patients and their relatives were informed that, participating to the study is totally up to them, their names will be written on data gathering forms but their personal information will only be used in this study and will stay classified.

\section{Evaluation of the Data}

Gathered data was evaluated through SPSS 22 software and it was presented in numbers, percentages, averages and standard deviations. The data was analyzed via Kolmogorov Smirnov test and it was determined that the data does not correspond to standard range. For this reason, in order to match the non-parametric test assumptions, chi square test, Mann-Whitney $U$ and Kruskal Wallis tests were utilized. Margin of error $(\alpha)$ was 005.

\begin{tabular}{|c|c|c|c|}
\hline $\begin{array}{l}\text { Introductory } \\
\text { Features }\end{array}$ & $\begin{array}{l}\text { Uncontrolled } \\
\text { Group }(n=51)\end{array}$ & $\begin{array}{l}\text { Controlled } \\
\text { Group }(n=43)\end{array}$ & $\begin{array}{l}\text { Test and } \\
\text { p value }\end{array}$ \\
\hline \multirow[t]{2}{*}{ Age } & $\begin{array}{l}\bar{X}=70.41 \pm 15.63 \\
(\min : 17, \max : 95)\end{array}$ & $\begin{array}{l}\bar{X}=69.51 \pm 18.18 \\
(\min : 23, \max : 89)\end{array}$ & $\begin{array}{l}\mathrm{X}^{2^{*}}=37.79 \\
\mathrm{p}=0.696\end{array}$ \\
\hline & $\mathrm{n}(\%)$ & $\mathrm{n}(\%)$ & \\
\hline \multicolumn{4}{|l|}{ Gender } \\
\hline Female & $20(39.2)$ & $10(23.3)$ & \multirow{2}{*}{$\begin{array}{l}X^{2}=2.75 \\
p=0.098\end{array}$} \\
\hline Male & $31(60.8)$ & $33(76.7)$ & \\
\hline \multicolumn{4}{|l|}{ Diagnosis } \\
\hline $\begin{array}{l}\text { Respiratory } \\
\text { Insufficiency }\end{array}$ & $34(66.7)$ & $26(60.5)$ & \multirow[t]{2}{*}{$\begin{array}{l}X^{2}=0.38 \\
p=0.533\end{array}$} \\
\hline $\begin{array}{l}\text { Other }{ }^{*}(\mathrm{ABY}, \\
\text { COLD }, \mathrm{HT}, \ldots)\end{array}$ & $48(94.16)$ & $40(93.07)$ & \\
\hline \multicolumn{4}{|l|}{ Previous Clinic } \\
\hline Emergency & $16(37.2)$ & $19(37.3)$ & \multirow{3}{*}{$\begin{array}{l}X^{2}=3.17 \\
p=0.205\end{array}$} \\
\hline $\begin{array}{l}\text { Intra-Hospital } \\
\text { Clinics }\end{array}$ & $26(60.5)$ & $26(51.0)$ & \\
\hline $\begin{array}{l}\text { Intra-hospital } \\
\text { ICU }\end{array}$ & $6(11.8)$ & $1(2.3)$ & \\
\hline \multicolumn{4}{|c|}{ Reason of Hospitalization } \\
\hline Trauma & $4(7.8)$ & $4(9.3)$ & \multirow{3}{*}{$\begin{array}{l}X^{2}=3.43 \\
p=0.488\end{array}$} \\
\hline Postop & $7(13.7)$ & $7(16.3)$ & \\
\hline $\begin{array}{l}\text { Internal } \\
\text { Diseases }\end{array}$ & $40(78.4)$ & $32(74.4)$ & \\
\hline
\end{tabular}

Table 1: Distribution of controlled and uncontrolled group patients according to introductory features.

${ }^{\star} \mathrm{X}^{2}=$ Chi-square

** Multiple diagnosis may fall to single patient 
Citation: Karagözoğlu Ş, Yildiz FT, Gürsoy S, Gülsoy Z, Süha BK, et al. (2018) The Effect of Bundle Adaptation Control on VAP Speed and Length of Hospital Stay in Avoiding the Ventilator Associated Pneumonia (VAP) at Anesthesia Intensive Care Unit. Int J Nurs Clin Pract 5: 295. doi: https://doi.org/10.15344/2394$4978 / 2018 / 295$

Page 4 of 7

\section{Findings}

It was determined that average age of the patients of uncontrolled group was $X=70.41 \pm 15.63,60.8 \%$ were males and $66.7 \%$ of them were diagnosed with respiratory insufficiency. It was also seen that $51 \%$ of the patients of this group were transferred from other clinics and $78.4 \%$ of them were hospitalized due to internal diseases. Average age of the patients in the controlled group was $X=69.51 \pm 18.18$, $76.7 \%$ of them were males and $60.5 \%$ of them were diagnosed with respiratory insufficiency. $60.5 \%$ of this group were transferred from other departments and $74.4 \%$ of them were hospitalized because of internal diseases. In terms of introductory features, there was no statistically meaningful difference between groups and participants of both groups had similar characteristics $(p>0.05)$.

It was found out that, in comparison with the patients of uncontrolled group $(\mathrm{X}=31.41 \pm 36.41)$, the average days of stay $(\mathrm{X}=11.41 \pm 12.29$, ) for the patients of controlled group, the difference was statistically highly meaningful $(\mathrm{p}=0.001)$. The number of days spent on mechanical ventilation by uncontrolled and controlled groups were $\mathrm{X}=27.52 \pm 34.03, \mathrm{X}=11.20 \pm 12.34$ respectively and the difference was statistically meaningful $(\mathrm{p}=0.013)$. While the VAP development percentage was $4.7 \%$ for the controlled group, the rate was $19.6 \%$ for the controlled group and the difference between groups was highly meaningful in statistical terms $(\mathrm{p}=0.035)$. With the uncontrolled group while the number of VAP development days on mechanical ventilation was 7.12 , it was 4.14 days for the controlled group and the difference is found to be statistically very meaningful $(\mathrm{p}=0.001)$ (Table 2).

When we analyze application of the ventilator bundle approaches according to shifts; it was seen that doctors and nurses elevated the bedhead around $30^{\circ}-45^{\circ}$ and did daily oral care with chlorhexidine without $100 \%$ adaptation. Daily sedation evaluation and peptic ulcer prophylaxis approaches were conducted at a rate of $100 \%$ at 08.00 16.00 shift but the rate decreased at other shifts. The least followed ventilator bundle approach was deep vein thrombosis prophylaxis and the application rates for $08.00-16.00,16.00-24.00$ and $24.00-08.00$ were $97.7 \%, 14 \%$ and $7 \%$ respectively (Table 3 ).

In our study, it was found out that the adaptation level of doctors and nurses working in intensive care unit at 08.00-16.00, 16.00-24.00 and $24.00-08.00$ is $99.54 \%, 65.02 \%$ and $45.12 \%$ respectively. The adaptation rate of ICU staff was $100 \%$ for elevation of the bedhead around $30^{\circ}-45^{\circ}$, and daily oral care with chlorhexidine; and adaptation rates for daily sedation evaluation approach, peptic ulcer prophylaxis approach and deep vein thrombosis prophylaxis approach were $41.86 \%, 68.03 \%$ and $39.56 \%$ respectively. Evaluating this data, it was calculated that the total adaptation level of doctors and nurses of ICU was $69.89 \%$ (Table 4 ).

When the VAP development condition was analyzed according to introductory features among controlled and uncontrolled groups, no statistically meaningful correlation was found ( $\mathrm{p}>0.05$ ) (Table 5).

\section{Discussion}

Though it is stated in the literature that ventilator bundle applications are effective in reducing VAP development speed $[1,3,9,27]$, it is also emphasized that in order to achieve significant reductions in VAP development speed, the adaptation level to the ventilator bundle must be $95 \%$ or over $[16,28]$. In this context, although the general adaptation rate to the ventilator bundle with the controlled group (69.89\%) (Table 4) is rather lower than the level recommended in the literature, while the VAP rate (19.6\%) and VAP speed (7.12/1000)

\begin{tabular}{|l|l|l|l|}
\hline & \multicolumn{1}{|c|}{$\begin{array}{c}\text { Uncontrolled Group } \\
(\mathrm{n}=51)\end{array}$} & $\begin{array}{c}\text { Controlled Group } \\
(\mathrm{n}=43)\end{array}$ & $\begin{array}{c}\text { Test and } \mathrm{p} \\
\text { value }\end{array}$ \\
\hline Number of Days Spent at Hospital & $\begin{array}{l}\bar{X}=31.41 \pm 36.41(\min : 2, \\
\text { max:161) }\end{array}$ & $\begin{array}{l}\bar{X}=11.41 \pm 12.29 \\
(\min : 2, \max : 61)\end{array}$ & $\begin{array}{l}\mathrm{U}^{*}=678.500 \\
\mathrm{p}=0.001\end{array}$ \\
\hline Time spent on Mechanical Ventilation & $\begin{array}{l}\bar{X}=27.52 \pm 34.03 \\
(\min : 1, \max : 161)\end{array}$ & $\begin{array}{l}\bar{X}=11.20 \pm 12.34 \\
(\min : 2, \max : 61)\end{array}$ & $\begin{array}{l}\mathrm{U}=768.500 \\
\mathrm{p}=0.013\end{array}$ \\
\hline VAP Rate & $\mathrm{n}(\%)$ & $\mathrm{n}(\%)$ & \\
\hline Yes & $10(19.6)$ & $2(4.7)$ & $\begin{array}{l}\mathrm{X}^{2}=4.68 \\
\mathrm{p}=0.035\end{array}$ \\
\hline No & $41(80.4)$ & $41(95.3)$ & $\begin{array}{l}\mathrm{t}^{* *}=8.76 \\
\mathrm{p}=0.001\end{array}$ \\
\hline VAP Speed & 7.12 & 4.14 & \\
\hline
\end{tabular}

Table 2: Comparison of number of days spent at hospital, the time spent on mechanical ventilation, VAP Rate and VAP Speed on uncontrolled and controlled.

\begin{tabular}{|c|c|c|c|c|c|c|}
\hline & \multirow{2}{*}{\multicolumn{2}{|c|}{$\begin{array}{c}\text { Shift } 08.00-16.00 \\
\text { Applier } \\
\text { Doctor - Nurse }\end{array}$}} & \multirow{2}{*}{\multicolumn{2}{|c|}{$\begin{array}{c}\text { Shift } 16.00-24.00 \\
\text { Applier } \\
\text { Doctor - Nurse }\end{array}$}} & \multirow{2}{*}{\multicolumn{2}{|c|}{$\begin{array}{c}\text { Shift } 24.00-08.00 \\
\text { Applier } \\
\text { Doctor - Nurse }\end{array}$}} \\
\hline & & & & & & \\
\hline & $\begin{array}{l}\text { Yes } \\
\text { n (\%) }\end{array}$ & $\begin{array}{l}\text { No } \\
\text { n (\%) }\end{array}$ & $\begin{array}{l}\text { Yes } \\
\mathrm{n}(\%)\end{array}$ & $\begin{array}{l}\text { No } \\
\mathrm{n}(\%)\end{array}$ & $\begin{array}{l}\text { Yes } \\
\mathrm{n}(\%)\end{array}$ & $\begin{array}{l}\text { No } \\
\text { n (\%) }\end{array}$ \\
\hline Elevation of Bedhead around $30^{\circ}-45^{\circ}$ & $43(100)$ & - & $4(100)$ & - & $43(100)$ & - \\
\hline Evaluation of Daily Sedation & $43(100)$ & - & $6(14.0)$ & $37(86.0)$ & $5(11.6)$ & $38(89.4)$ \\
\hline Peptic Ulcer Prophylaxis & $43(100)$ & - & $42(97.1)$ & $1(2.3)$ & $3(7.0)$ & $40(93.0)$ \\
\hline Deep Vein Thrombosis Prophylaxis & $42(97.7)$ & $1(2.3)$ & $6(14.0)$ & $37(86.0)$ & $3(7.0)$ & $40(93.0)$ \\
\hline Daily Oral Care with Chlorhexidine & $43(100)$ & - & $43(100)$ & - & $43(100)$ & - \\
\hline
\end{tabular}

Table 3: Doctors' and Nurses' distribution of ventilator bundle approaches application rates according to shifts. 
Citation: Karagözoğlu Ş, Yildiz FT, Gürsoy S, Gülsoy Z, Süha BK, et al. (2018) The Effect of Bundle Adaptation Control on VAP Speed and Length of Hospital Stay in Avoiding the Ventilator Associated Pneumonia (VAP) at Anesthesia Intensive Care Unit. Int J Nurs Clin Pract 5: 295. doi: https://doi.org/10.15344/2394$4978 / 2018 / 295$

Page 5 of 7

of the uncontrolled group of our study is higher, it is determined that the VAP rate (4.7\%) and VAP speed (4.14/1000) of controlled group reduced statistically meaningfully (Table 2 ). In our study, it was proven that VAP development speed was $43 \%$ lower with the controlled group and ventilator bundle adaptation control reduces VAP development by $75 \%$. Reading the related literature, it can be seen that there are a lot of studies that supports our study, and these studies show that with proper application of ventilator bundles $[4,12,14,15,19-26,29-35]$ and higher adaptation of the staff to them $[14,15,18,20,23,24,26,31$ 38] VAP rate and speed decreases. However, diversely from our study, ventilator application bundles of different approaches and various numbers of them were utilized in those studies [4,12,14,15,1926,29-35] and bundles were mostly applied by nurses [19-26]. Yet, it is of high significance to utilize the scientifically proven up-to-date ventilator bundle applications by multi-discipliner teams. In this context, the five approaches ventilator bundle, which was updated by IHI, was applied by a multi-discipliner team within our study, and relatively high success was achieved on VAP development rate and decreasing the incidence rate via bundle applications and bundle adaptation control processes.

The preventive methods applied to patients, who are staying at ICUs on mechanical ventilators, is very important, and the two most important indicators of effectiveness of treatment and care are number of the days spent at hospital and number of days spent on mechanical ventilation. In this context, throughout the study it was found out that, the number of days spent at hospital and on mechanical ventilation was significantly and statistically fewer $(\mathrm{p}<0.05)$ with the controlled group which was controlled by our multi-discipliner research team, and ventilator bundle application control reduced the number of days spent at hospital by $64 \%$ and the time spent on mechanical ventilator by $61 \%$ (Table 2 ). Similar studies about this issue responsively showed that VAP speed reduces thanks to ventilator bundle applications and this reduction results in fewer days spent at hospital shorter time periods on mechanical ventilation $[4,12,13,19,22,24,26,29,33]$. Accordingly, with all these findings, it would not be wrong to state that, in giving effective and efficient healthcare VAP preventive bundles are vitally required and of high importance.

The ventilation bundles, which include some approaches of vital importance and help to achieve success when applied totally, are becoming more and more important and recommended more often in national and international guidelines. In this context, when the application adaptation of doctors and nurses was inspected according to their shifts we saw that; $30^{\circ}-45^{\circ}$ elevation of bedheads and daily oral care with chlorhexidine applications were conducted at the rate of $100 \%$, daily sedation evaluation and peptic ulcer prophylaxis approaches were done at the rate of $100 \%$ at $08.00-16.00$ shift and the rate for these two approaches declined at other shifts. While the application rate was rather high at 08.00-16.00 shift, the rate declined dramatically at evening (14\%) and night (7\%) shifts, so the lowest rate of application was for deep vein prophylaxis approach (Table 3). Similar studies in the literature show similar results to ours $[19,22]$. When the methods of these studies are examined, it can be seen that in VAP prevention, ventilator bundle adaptation parameter was taken into consideration. In our study, another parameter is taken into the

\begin{tabular}{|l|c|c|c|c|}
\hline & $\begin{array}{c}\text { Shift } 08.00-16.00 \\
\%\end{array}$ & $\begin{array}{c}\text { Shift } 16.00-24.00 \\
\%\end{array}$ & $\begin{array}{c}\text { Shift 24.00-08.00 } \\
\%\end{array}$ & $\begin{array}{c}\text { General Adaptation (Total) } \\
\%\end{array}$ \\
\hline Elevation of Bedheadaround $30^{\circ}-45^{\circ}$ & 100 & 100 & 100 & 100 \\
\hline Evaluation of Daily Sedation & 100 & 14.0 & 11.6 & 41.86 \\
\hline Peptic Ulcer Prophylaxis & 100 & 97.1 & 7.0 & 68.03 \\
\hline Deep Vein Thrombosis Prophylaxis & 97.7 & 14.0 & 7.0 & 39.56 \\
\hline Daily Oral Care with Chlorhexidine & 100 & 100 & 100 & 100 \\
\hline General Adaptation & 99.54 & 65.02 & 45.12 & 69.89 \\
\hline
\end{tabular}

Table 4: Doctors' and Nurses' distribution of adaptation to ventilator bundle approaches according to shifts.

\begin{tabular}{|c|c|c|c|c|c|}
\hline & & \multicolumn{4}{|c|}{ VAP Development Condition } \\
\hline & & \multicolumn{2}{|c|}{ UncontrolledGroup } & \multicolumn{2}{|c|}{ ControlledGroup } \\
\hline & & Yes & No & Yes & No \\
\hline & & $\mathrm{n}(\%)$ & $\mathrm{n}(\%)$ & n (\%) & $\mathrm{n}(\%)$ \\
\hline \multirow[t]{2}{*}{ Gender } & Female & $4(40.0)$ & $16(39.2)$ & - & $10(24.4)$ \\
\hline & Male & $6(60.0)$ & $25(60.8)$ & $2(100)$ & $31(75.6)$ \\
\hline \multicolumn{2}{|l|}{ Test and $p$ value } & \multicolumn{2}{|c|}{$\mathrm{X}^{2^{*}}=0.003 ; \mathrm{p}=1.000$} & \multicolumn{2}{|c|}{$\mathrm{X}^{2}=0.636 ; \mathrm{p}=1.000$} \\
\hline \multirow[t]{3}{*}{ PreviousClinic } & Emergency & $6(60.0)$ & $13(31.7)$ & $2(100)$ & $14(34.1)$ \\
\hline & Intra-HospitalClinic & $3(30.0)$ & $23(56.1)$ & - & $26(63.4)$ \\
\hline & Intra-Hospital Another ICU & $1(10.0)$ & $5(12.2)$ & - & $1(2.5)$ \\
\hline \multicolumn{2}{|l|}{ Test and $p$ value } & \multicolumn{2}{|c|}{$\mathrm{X}^{2}=3.540 ; \mathrm{p}=0.170$} & \multicolumn{2}{|c|}{$\mathrm{X}^{2}=2.834 ; \mathrm{p}=0.242$} \\
\hline \multirow{3}{*}{$\begin{array}{l}\text { Reason of } \\
\text { Hospitalization }\end{array}$} & Trauma & - & $2(4.9)$ & $1(50)$ & $3(7.3)$ \\
\hline & Postop & $4(40)$ & $5(12.2)$ & - & $7(17.1)$ \\
\hline & Internaldiseases & $6(60)$ & $34(82.9)$ & $1(50)$ & $31(75.6)$ \\
\hline \multicolumn{2}{|l|}{ Test and $\mathrm{p}$ value } & \multicolumn{2}{|c|}{$\mathrm{X}^{2}=4.549 ; \mathrm{p}=0.103$} & \multicolumn{2}{|c|}{$\mathrm{X}^{2}=4.244 ; \mathrm{p}=0.120$} \\
\hline
\end{tabular}

Table 5: VAP development condition with uncontrolled and controlled groups according to introductory features. 
Citation: Karagözoğlu Ş, Yildiz FT, Gürsoy S, Gülsoy Z, Süha BK, et al. (2018) The Effect of Bundle Adaptation Control on VAP Speed and Length of Hospital Stay in Avoiding the Ventilator Associated Pneumonia (VAP) at Anesthesia Intensive Care Unit. Int J Nurs Clin Pract 5: 295. doi: https://doi.org/10.15344/2394$4978 / 2018 / 295$

Page 6 of 7

equation in order to support and strengthen the ventilator bundle adaptation parameter. Our new parameter is that the doctors and nurses working at ICU for our study, recorded their adaptation level to ventilator bundle application on their own. With this approach, the doctors and nurses were expected to take responsibility in including the ventilator bundle into clinic routines and their awareness level was expected to be increased. In this context, it is obvious that ventilator bundle application rate is pretty high with the staff of 08.00-16.00 shift and the application is included into the routine. However, at evening and night shifts, application rate of especially the deep vein thrombosis prophylaxis approach declined significantly and increasing work load and fewer staff number was speculated to be the reason of this decline.

In all healthcare institutes, application of VAP preventive bundles is at increase but the approaches and numbers included into the bundles differ. Within our study, IHI's updated five approaches bundle was utilized, and it was observed that elevation of bedhead around $30^{\circ}$. $45^{\circ}$, and oral care with chlorhexidine approaches were complied with no error (Table 4). Through the literature, it can be seen in similar studies that in ventilator bundle approaches the two mentioned above are likely to be the most compliable via application and training $[14,23,25]$. In parallel with these findings, it is also known that these approaches, which are included in different ventilation bundles and can be fully complied to, are responsibility of nurses. For this reason, non-stop nursing service may result in appropriate application of these approaches.

\section{Conclusion and Recommendations}

Within our study, it was found out that the introductory features of controlled and uncontrolled groups were similar. However, while the adaptation rate of controlled group was lower than the average of the literature, and VAP rate and speed was higher with uncontrolled group, it was determined that with the controlled group VAP rate and speed was significantly lower, and this difference is statistically meaningful. In the study, it was determined that the controlled group's, which was inspected by a multi-discipliner team about ventilator bundle application, number of days and the time spent on mechanical ventilation were statistically lower than of the uncontrolled group. At all shifts, it was observed that elevation of bedhead around $30^{\circ}$. $45^{\circ}$, and oral care with chlorhexidine approaches were complied with no error, and the least applied approach was deep vein thrombosis prophylaxis. In line with these results, it is thought that the control of the ventilation bundles which were applied to patients had a positive effect on reducing VAP speed and the number of days spent at hospital and recording the ventilation bundle approaches daily by the ICU staff by themselves increased their awareness level about teamwork.

In accordance with our findings (1) application and generalizing of updated ventilator bundles, (2) running regular inspections in order to increase adaptation of staff, (3) strengthening team work in order to increase application and adaptation of ventilator bundles, and (4) increasing number of staffs in order to reduce the workload at evening and night shifts, can be recommended.

\section{Limits}

The data gathered through this study is limited to the period when the study was conducted.

\section{Contribution of Authors}

Planning of the study; Karagozoglu Ş., Gursoy S and Tok Yildiz F. Informing the ICU doctors and nurses about approaches in redesigned ventilator bundle; Gursoy S., Gulsoy Z., Elaldi N. and Arslan G. Gathering the data; Karagooglu Ş and Tok Yildiz F. Creating the Database; Suha B.C., Kocyigit H. Data Entry; Karagozoglu Ş., and Tok Yildiz F. Analyzing the Data; Karagozoglu S and Tok Yildiz F. Reading the Paper and Publication; Karagozoglu Ş. and TokYildiz F.

\section{Acknowledgements}

The authors thank Cumhuriyet University Scientific Research Projects (CÜBAP) for their generous support to this project. The authors are sincerely grateful to the people and their families who participated in the project.

\section{Funding}

This project is funded by CÜBAP, Project Number: SBF-041.

\section{Competing Interests}

The authors declare that they have no competing interests.

\section{References}

1. Institute for Healthcare Improvement (2012) How- to Guide: Prevent Ventilator- Associated Pneumonia.

2. Klompas M, Branson R, Eichenwald EC, Greene LR, Howell MD, et al. (2014) Strategies to prevent ventilator-associated pneumonia in acute care hospitals: 2014 update. Infect Control Hosp Epidemiol 35: 915-936.

3. Dodek P, Keenan S, Cook D, Heyland D, Jacka M, et al. (2004) EvidenceBased Clinical Practice Guideline for Prevention of Vetilator-Associated Pneumonia. Ann Intern Med. 141:305-311.

4. Al-Thaqafy MS, El-Saed A, Arabi YM, Balkhy HH (2014) Association of compliance of ventilator bundle with incidence of ventilator-associated pneumonia and ventilator utilization among critical patients over 4 years. Ann Thorac Med 9: 221-226.

5. Uckay I, Ahmed QA, Sax H, Pittet D (2008) Ventilator-associated pneumonia as a quality indicator for patient safety? Clin Infect Dis 46: 557-563.

6. Şardan Y, Oku FC, Kabasakal E, Doluküp I (2014) National Hospital Infections Surveillance Network Summary Report, Republic of Turkey Ministry of Health Directorate General of Health Services Department of Health Services Standards.

7. Donmez NF, Kanyılmaz D, Tiryaki C, Yılmaz S, Dikmen B, et al. (2012) Evidence-based guidelines for the prevention of ventilator associated pneumonia: results of knowledge test among anesthesia residents employed in ICU. Journal of the Turkish Anaesthesiology and Intensive Care Society 40: 202-211.

8. Alcan A, Korkmaz F (2015) Ventilator associated pneumonia inhibition: care bundle approach. İzmir Üniversitesi Tıp Dergisi 3: 35-47.

9. Centers for Disease Control and Prevention (2018) Healthcare-associated Infectons Ventilator-associated Pneumonia.

10. Resar R, Griffin FA, Haraden C, Nolan TW (2012) Using Care Bundles to Improve Health Care Quality IHI Innovation Series white paper.

11. Kurutkan M (2014) Practice of patient safety in the context of evidence based practices: care bundles (Basic prevention bundle). Sağlık Akademisyenleri Dergisi 1: 83-88.

12. Shitrit $P$, Meirson $M$, Mendelson $G$, Chower $M$ (2015) Intervention to reduce ventilator-associated pneumonia in individuals on long-term ventilation by introducing a customized bundle. J Am Geriatr Soc 63: 2089-2093.

13. Rello J, Lode H, Cornaglia G, Masterton R, VAP Care Bundle Contriutors, et al. (2010) A European care bundle for prevention of ventilator-associated pneumonia. Intensive Care Med 36: 773-780. 
Citation: Karagözoğlu Ş, Yildiz FT, Gürsoy S, Gülsoy Z, Süha BK, et al. (2018) The Effect of Bundle Adaptation Control on VAP Speed and Length of Hospital Stay in Avoiding the Ventilator Associated Pneumonia (VAP) at Anesthesia Intensive Care Unit. Int J Nurs Clin Pract 5: 295. doi: https://doi.org/10.15344/2394$4978 / 2018 / 295$

Page 7 of 7

14. Saber SM, Aly WW, Bassim HH, Said AS (2013) Implementation of ventilator bundle in prevention of ventilator associated pneumonia. Middle East Journal of Age and Ageing 10: 29-34

15. Alsadat R, Al-Bardan H, Mazloum MN, Shamah AA, Eltayeb MF, et al. (2012) Use of ventilator associated pneumonia bundle and statistical process control chart to decrease VAP rate in Syria. Avicenna J Med 2: 79-83

16. Caserta RA, Marra AR, DDurao MS, Silva CV, Santos OFP, et al (2012) A program for sustained improvement in preventing ventilator associated pneumonia in an intensive care setting. BMC Infectious Diseases 12: 234242.

17. Cason C, Tyner T, Saunders S, Broome L, Centers for Disease Control and Prevention, et al. (2007) Nurses' implementation of guidelines for ventialtor- associated pnuemonia from the Centers for Disease Control and Prevention. Am J Crit Care 16: 28-38.

18. Y Ildı I (2013) Application of Ventilator Related Pneumonia Prevention Bundle and Evaluation of Contribution of Education in Anesthesia and Neurology Intensive Care Units, Ondokuz Mayıs University Faculty of Medicine Department of Infectious Diseases Specialization Thesis, Samsun.

19. Sungur $G$ (2011) The effect of personnel training in the use of evidence based guidance to prevent ventilator associated pneumonia in the Intensive Care Unit of the Internal Medicine Erciyes University Health Sciences Institute Nursing Department, PhD Thesis, Internal Medicine Nursing. Kayseri.

20. Kilınçalp S (2010) Assessment of ventilator related pneumonia prevention bundle in intensive care unit of internal medicine, Department of Internal Medicine, Hacettepe University Faculty of Medicine. Specialization thesis, Ankara.

21. Curtin LJ (2007) Nursing strategies in reducing ventilator associated pneumonia : program evaluation; a dissertation. Ph.D. University of Massachusetts Boston.

22. Solak Grassie S, Kayaaslan B, Çetin Gevrek S, Kumral D, Emre C, et al. (2016) In our intensive care unit the experience of the checklist use to prevent ventilator associated pneumonia. Türk Yoğun Bakım Derneği Dergisi 14: 13-17.

23. Ismail R, Zahran E (2015) The effect of nurses training on ventilatorassociated pneumonia (VAP) prevention bundle on VAP incidence rate at a critical care unit. Journal of Nursing Education and Practice 5: 42-48.

24. Hatler C, Mast D, Corderella J, Mitchell G, Howerd K, et al. (2006) Using evidence and process improvement strategies to enhance healthcare outcomes for the critically ill a pilot study. American Journal of Critical Care 15: $549-555$

25. Sachetti A, Rech V, Dias AS, Fontana C, Barbosa Gda L, et al (2014) Adherence to the items in a bundle for the prevention of ventilatorassociated pneumonia. Rev Bras Ter Intensiva 26: 355-3509.

26. Okgun Alcan A, Demir Korkmaz F, Uyar M (2016) Prevention of ventilatorassociated pneumonia: Use of the care bundle approach. Am J Infect Control 44: e173-e176.

27. Ture Z, Alp E (2018) Infection control bundles for the prevention of hospital infections. Mediterranean Journal of Infection Microbes and Antimicrobials.

28. Lambert M, Palomar M, Agodi A, Heismary M, Lepape A, et al. (2013) Prevention of ventilator- associated pneumonia in intensive care unit: an international online survey. Antimicrobial Resistance and Infection Control 2: 9

29. Azab SF, Sherbiny HS, Saleh SH, Elsaeed WF, Elshafiey WF, et al. (2015) Reducing ventilator-associated pneumonia in neonatal intensive care unit using "VAP prevention Bundle": a cohort study. BMC Infect Dis 15: 314.

30. De Cristofano A, Peuchot V, Canepari A, Franco V, Perez A, et al. (2016) Implementation of a ventilator-associated pneumonia prevention bundle in a single PICU. Pediatr Crit Care Med 17: 451-456.

31. Youngquist P, Caroll M, Farber M, Macy D, Madrid P, et al (2007) Implementing a ventilator bundle in a community hospital. Jt Comm J Qual Patient Saf 33: 219-225.

32. Marini AL, Khan R, Mundekkadan S (2016) Multifaceted bundle interventions shown effective in reducing VAP rates in our multidisciplinary ICUs. BMJ Qual Improv Rep.

33. Khan R, Al-Dorzi HM, Al-Attas K, Ahmed FW, Marini AM, et al. (2016) The impact of implementing multifaceted interventions on the prevention of ventilator-associated pneumonia. Am J Infect Control 44: 320-326.
34. Eom JS, Lee MS, Chun HK, Choi HJJ, Jung SY, et al (2014) The impact of a ventilator bundle on preventing ventilator-associated pneumonia: A multicenter study. American Journal of Infection Control 42: 34-37.

35. Rello J, Afonso E, Lisboa T, Ricart M, Balsere B, et al (2013) A care bundle approach for prevention of ventilator-associated pneumonia. Clin Microbiol Infect 19: 363-369.

36. Resar R, Pronovost P, Haraden C, Simmonds T, Rainey T, et al (2005) Using a bundle approach to improve ventilator care processes and reduce ventilator-associated pneumonia. Jt Comm J Qual Patient Saf 31: 243-248.

37. Hampton D, Griffith D, Howard A (2005) Evidence-based clinical improvement for mechanically ventilated patients. Rehabilitation Nursing 30: 160-165.

38. Curden E, Boyce C, Woodman H, Bray B (2005) An evaluation of the impact of ventilator care bundle. British Association of Critical Care Nurses. Nurs Crit Care 10: 242-246. 